УДК 621.039 .58

Ал-й П. Шугайло, М. А. Мустафин, Ал-р П. Шугайло, Д. И. Рыжов, О. И. Жабин

Государственный научно-технический центр по ядерной и радиационной безопасности, г. Киев, Украина

Основные результаты

оценки целостности

теплообменных трубок

парогенератора

энергоблока № 3

Ривненской АЭС в процессе управления аварией

Оценка целостности теплообменных трубок (ТОТ) с учетом их текущего технического состояния в условиях аварии с осушением парогенератора (ПГ) имеет существенное значение в продлении срока эксплуатации ПГ и усовершенствовании стратегий управления авариями.

Представлены основные результаты исследований теплообменной поверхности ПГ энергоблока № 3 РАЭС с целью оценки целостности ТОТ в условиях аварий, приводящих к полному или частичному осушению теплообменной поверхности.

Ключевые слова: парогенератор, теплообменная поверхность, стратегия управления аварией.

Ол-й П. Шугайло, М. А. Мустафін, Ол-р П. Шугайло, Д. І. Рижов, о. І. Жабін

Основні результати оцінки цілісності теплообмінних трубок парогенератора енергоблока № 3 Рівненської AEC у процесі управління аварією

Оцінка цілісності теплообмінних трубок (ТОТ) з урахуванням їх поточного технічного стану в умовах аварії з осушенням парогенератора (ПГ) має істотне значення у продовженні строку експлуатації ПГ і вдосконаленні стратегій управління аваріями.

Наведено основні результати досліджень теплообмінної поверхні ПГ енергоблока № 3 PAEC з метою оцінки цілісності ТОТ в умовах аварій, що призводять до повного або часткового осушення теплообмінної поверхні.

Ключові слова: парогенератор, теплообмінна поверхня, стратегія управління аварією.

() Ал-й П. Шугайло, М. А. Мустафин, Ал-р П. Шугайло, Д. И. Рыжов О. И. Жабин, 2017
П

ри аварийных сценариях, связанных с потерей теплоотвода вторым контуром, необходимо восстановление подпитки парогенераторов (ПГ), в том числе и после существенного снижения уровня в нем. Регулирование подпитки ПГ - одна из важнейших стратегий управления авариями, при этом целостность теплообменных трубок (ТОТ) имеет прямое влияние на выбор стратегии преодоления аварийных последствий.

Целью данной статьи является представление полученных результатов оценки целостности ТОТ в условиях аварии с осушением ПГ с учетом текущего технического состояния ТОТ. Результаты важны с точки зрения формирования подходов к усовершенствованию стратегий управления авариями.

Оценка целостности теплообменных ТОТ выполнена в следующей последовательности:

теплогидравлический расчет (количественный анализ) для выбранных представительных сценариев;

расчет прочности - разработка и верификация расчетной модели ТОТ, определение напряженно-деформированного состояния (НДС) трубок при нестационарном режиме протекания аварии;

анализ результатов оценки целостности.

\section{Теплогидравлический анализ}

Постановка задачи. Согласно требованиям инструкций по ликвидации аварий и аварийных ситуаций на реакторной установке (РУ), действия по восстановлению подпитки парогенераторов предписаны процедурами ВФТ-1.1 и АР3-0.0 [1]. При этом ограничивающим фактором с точки зрения времени восстановления подпитки ПГ являются не параметры среды в ПГ (давление, температура, уровень воды), а эффективность теплоотвода для снижения температуры теплоносителя первого контура и, соответственно, охлаждения активной зоны. Поскольку к моменту восстановления подпитки в ПГ поверхность теплообмена со стороны второго контура может быть частично или полностью оголена, подача холодной воды в ПГ может привести к возникновению сушественных термических напряжений на теплообменных трубках ПГ, в связи с чем возникает необходимость анализа влияния залива холодной воды на целостность трубчатки.

Выбор расчетного сценария для анализа. Из множества сценариев развития исходных событий (ИС), сопровождающихся значительным снижением уровня в ПГ (например, разрыв трубопровода питательной воды (ПВ) между ПГ и последним по ходу среды обратным клапаном, отключение насоса основной питательной воды, нарушения в системе основной питательной воды, приводящие к прекращению подачи ПВ в один ПГ), наибольший интерес с точки зрения подачи воды в частично или полностью осушенный ПГ представляют те сценарии, которые приводят к одновременной потере подпитки всех ПГ. К таким сценариям относятся сценарии запроектных аварий «Полная потеря питательной воды», а также «Полное обесточивание энергоблока».

В целом оба указанных сценария развиваются подобно друг другу, однако в случае полной потери ПВ имеется возможность организовать охлаждение активной зоны по первому контуру (со сбросом теплоносителя через ИПУ КД или систему аварийного газоудаления с реализацией подпитки от САОЗ ВД). В то же время, при полном обесточивании единственным способом охлаждения активной 
зоны до восстановления электроснабжения является подача воды в ПГ путем сброса давления в ПГ и слива воды из деаэраторов и/или подачи воды от мобильных насосных установок. При этом давление в первом контуре может превышать номинальное вследствие разогрева теплоносителя первого контура, что позволяет получить максимальный перепад давления между первым и вторым контуром.

На основании результатов качественного анализа исходных событий для дальнейшего расчетного анализа в качестве наиболее представительного ИС выбрано полное обесточивание энергоблока. Для оценки влияния времени восстановления подачи воды в ПГ рассматриваются два сценария: с восстановлением подачи воды в один ПГ на 2500-й секунде расчета (сценарий 1) и на 9000-й секунде (сценарий 2). Расход ПВ принят равным $75 \mathrm{~m}^{3} /$ ч, подача осуществляется по линии аварийной питательной воды. Температура подаваемой воды консервативно принята равной $5{ }^{\circ} \mathrm{C}$, как минимально возможная согласно [2].

Результаты анализа. Оба рассмотренных нестационарных режима ПГ (сценарий 1 и сценарий 2) характеризуются изменением параметров среды первого и второго контуров (внутреннее давление $P$, температура $T$, коэффициент теплоотдачи $\alpha$ ). Поскольку в обоих сценариях переходные процессы подобны, для дальнейшего прочностного анализа и оценки целостности ТОТ выбран сценарий 1.

Анализ поведения теплогидравлических параметров в рассматриваемом сценарии 1 выполнен с использованием расчетного кода RELAP5/Mod.3.2.

По результатам теплогидравлического расчета установлено, что при подаче аварийной питательной воды с температурой $5{ }^{\circ} \mathrm{C}$ температура воды второго контура в верхнем объеме трубчатки находится в диапазоне $278-295{ }^{\circ} \mathrm{C}$.

Отметим, что расчетный код RELAP5 является системным теплогидравлическим кодом в сосредоточенных параметрах, где параметры усредняются в расчетных узлах модели (контрольных объемах и соединениях), и расчетные значения температуры в контрольных объемах, моделирующих соответствующую часть второго контура ПГ, представляют собой некую «усредненную» температуру смеси, что приводит к получению оптимистичных (с точки зрения термических напряжений) условий на теплообменных трубках ПГ и не дает четкого представления о локальных параметрах.
Так как при выполнении расчетных анализов использовалась нодализационная схема ПГ, которая имеет довольно грубую разбивку парового пространства ПГ, результаты теплогидравлического анализа не могут реалистично показать распределение температур по объему ПГ в случае аварии при подаче холодной воды в паровое пространство осушенного ПГ. Данную неопределенность необходимо принимать во внимание при оценке целостности трубок ТОТ по результатам прочностного анализа.

С учетом полученных результатов теплогидравлического анализа, прочностные расчеты с целью оценки целостности трубок ТОТ выполнены для следующих граничных случаев:

1) «консервативного» (с точки зрения термических напряжений) - в качестве граничных условий по температуре на внешней поверхности теплообменной трубки принимается минимальное значение температуры, соответствующее температуре, подаваемой в ПГ аварийной питательной воды с температурой $5{ }^{\circ} \mathrm{C}$;

2) «оптимистичного» (с точки зрения термических напряжений) - в качестве граничных условий по температуре принимаются результаты расчетов, выполненных в коде RELAP. При подаче аварийной питательной воды с температурой $5{ }^{\circ} \mathrm{C}$ температура воды второго контура в верхнем объеме трубчатки находится в диапазоне $278-295{ }^{\circ} \mathrm{C}$.

\section{Расчет прочности и оценка целостности}

Описание расчетной модели, принятые упрощения и допущения. На основании анализа проектной документации в среде Designmodeller, входящей в состав расчетного комплекса ANSYS, создана геометрическая модель семи линий теплообменных трубок с фрагментами цилиндрических частей «холодного» и «горячего» коллекторов.

Исходя из условий симметрии, «холодный» и «горячий» коллекторы первого контура с целью консервативного определения влияния температурных расширений коллектора на исследуемые линии ТОТ смоделированы в виде полукруглого сегмента перфорированной цилиндрической части коллекторов высотой 40 мм (рис. 1). Начальные перемещения ТОТ в районе коллекторов вследствие их расширения при нагреве учтены консервативно (в упрощенном виде).

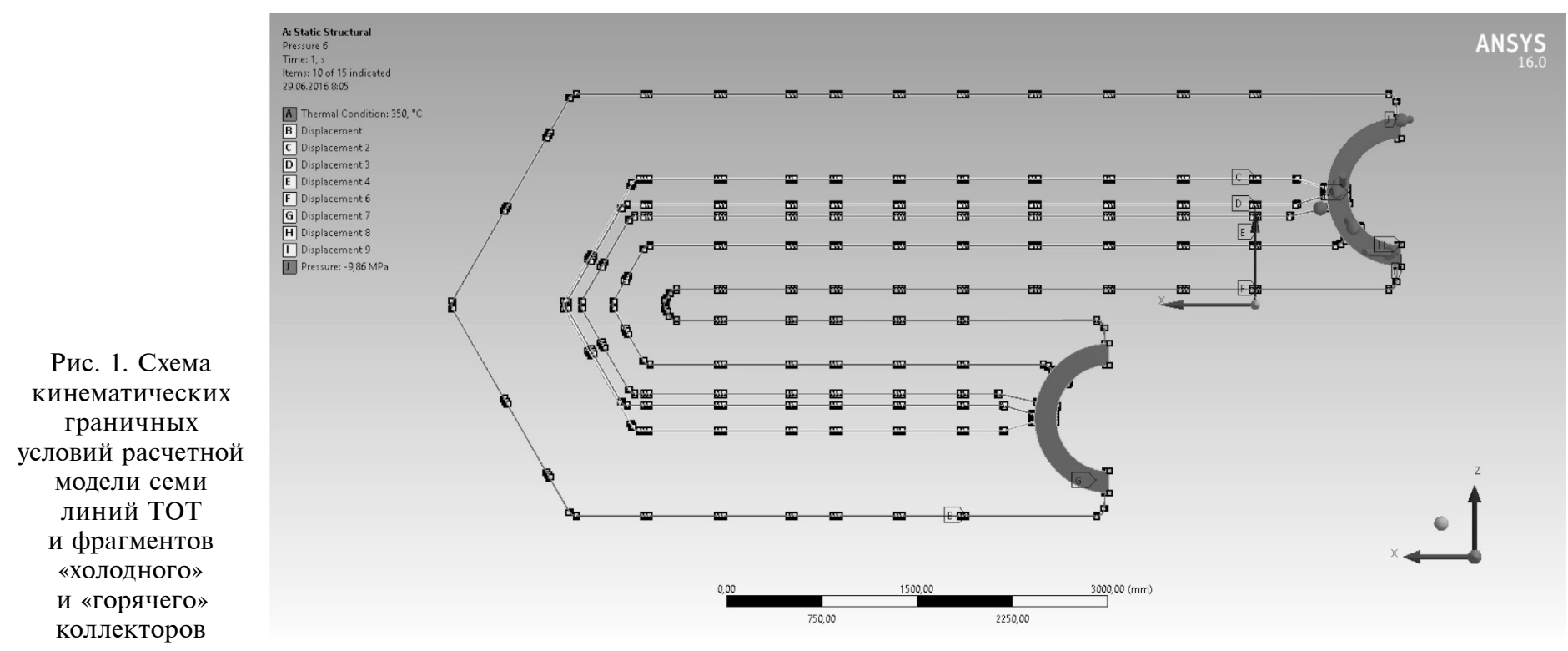




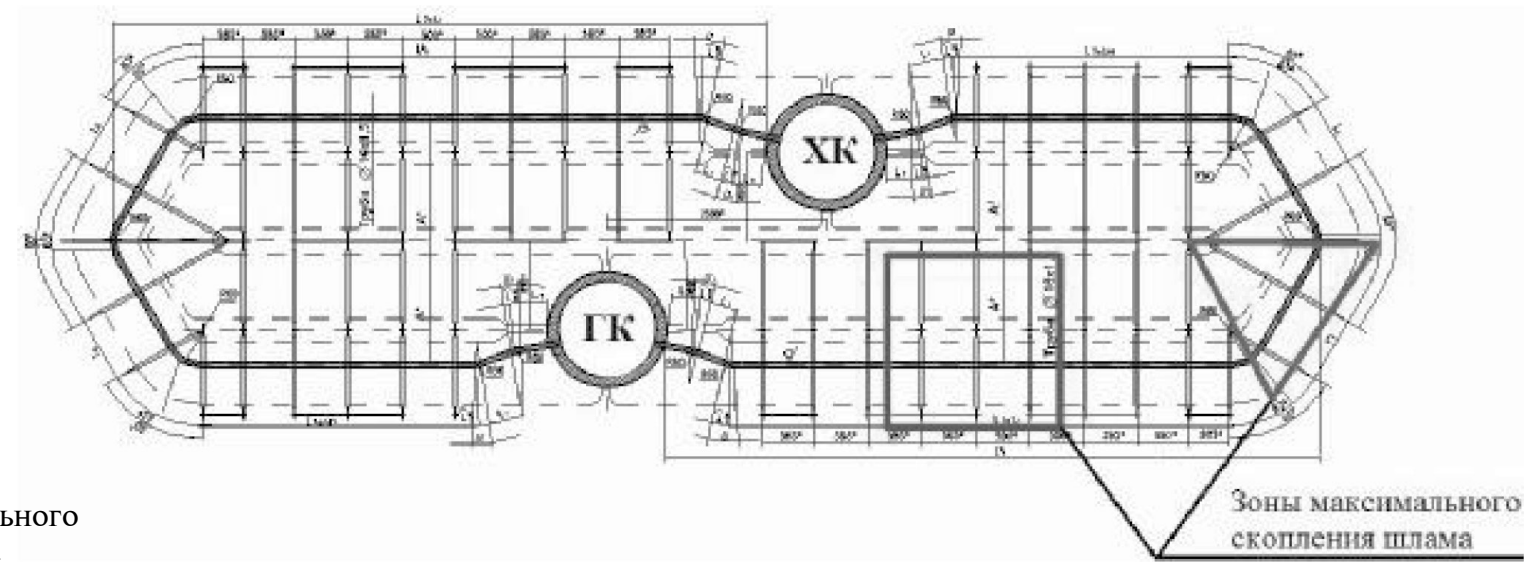

Рис. 2. Зоны максимального скопления шлама

Определение дополнительных нагрузок. Для уточне-

Для детального анализа НДС были выбраны три ТОТ внешнего и четыре TOT внутреннего U-образного пучка. Выбор данных ТОТ обусловлен геометрической формой (выбранные трубки охватывают все разновидности форм ТОТ по трассировке) и максимально большими расстояниями между опорами ТОТ.

Особое внимание уделено корректному моделированию граничных условий взаимодействия трубок с опорными элементами. Граничными условиями на торцах трубок в данном расчете являются перемещения, обусловленные радиальным температурным расширением фрагментов созданной модели коллекторов. Следует отметить, что все опорные элементы ТОТ спроектированы с учетом температурного расширения линий ТОТ в процессе эксплуатации.

На первом этапе для созданной модели трубок ТОТ определены значения напряжений в характерных сечениях (решена задача статической прочности при параметрах нормальных условий эксплуатации). Произведена итерационная верификация созданной модели с применением имеющегося решения для энергоблока № 1 Запорожской АЭС.

На втором этапе, на основе результатов верификации, а также с учетом реальной работы ТОТ в условиях температурных нагрузок выполнена корректировка граничных условий взаимодействия линий ТОТ с опорными элементами. ния нагрузок на трубки теплообменной поверхности выполнен дополнительный анализ текущего состояния ПГ Ривненской АЭС и рассмотрены статистика выхода из строя теплообменных трубок (для всех АЭС Украины), оценка состояния ТОТ ПГ, результаты вихретокового контроля, данные выполненных металлографических исследований.

Результаты анализа показали следующее:

ПГ эксплуатируются в тяжелых коррозионных условиях;

в процессе эксплуатации парогенераторов ПГВ-1000М имеются различные случаи повреждения ТОТ;

наблюдается массовое повреждение ТОТ во второй полуокружности в зоне между первой и четвертой дистанционирующими решетками от горячего коллектора (рис. 2);

скопление шлама может оказывать на ТОТ дополнительное воздействие в виде дополнительного веса на погонный метр трубки, влиять на условия закрепления трубки в опорах и т. д. (рис. 3);

коренной причиной повреждений ТОТ могут быть условия эксплуатации ПГ, а определяющим фактором - недопустимый уровень удельной загрязненности отложениями теплообменных труб ПГ;

в местах отложений и скоплений шламов концентрируются негативные факторы, приводящие к ускоренной
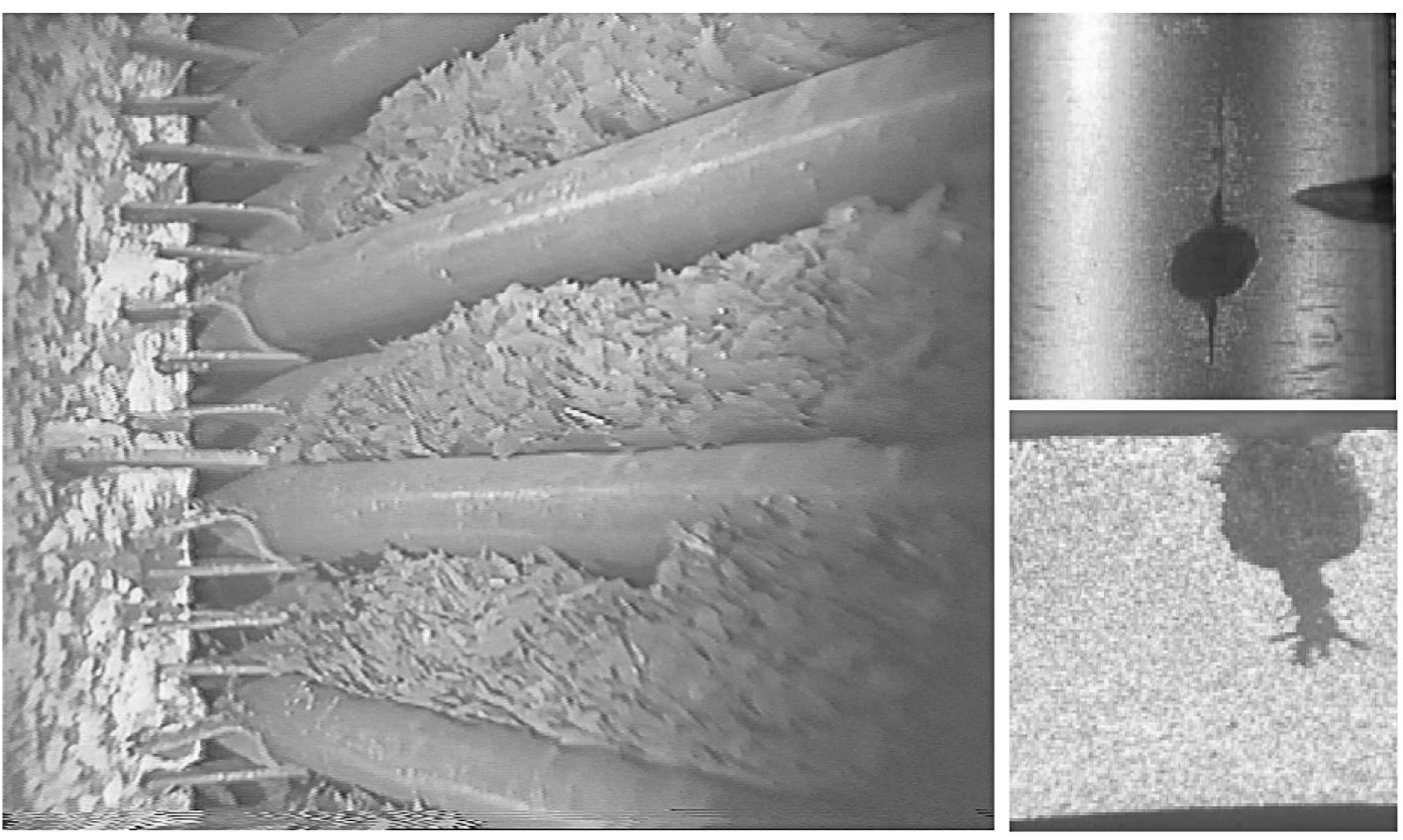

Рис. 3. Локальная зона скопления шлама в объеме парогенераторов; примеры язвенной коррозии ТОТ ПГ 
Рис. 4. Схема

моделируемого локального утончения стенки на $20 \%$
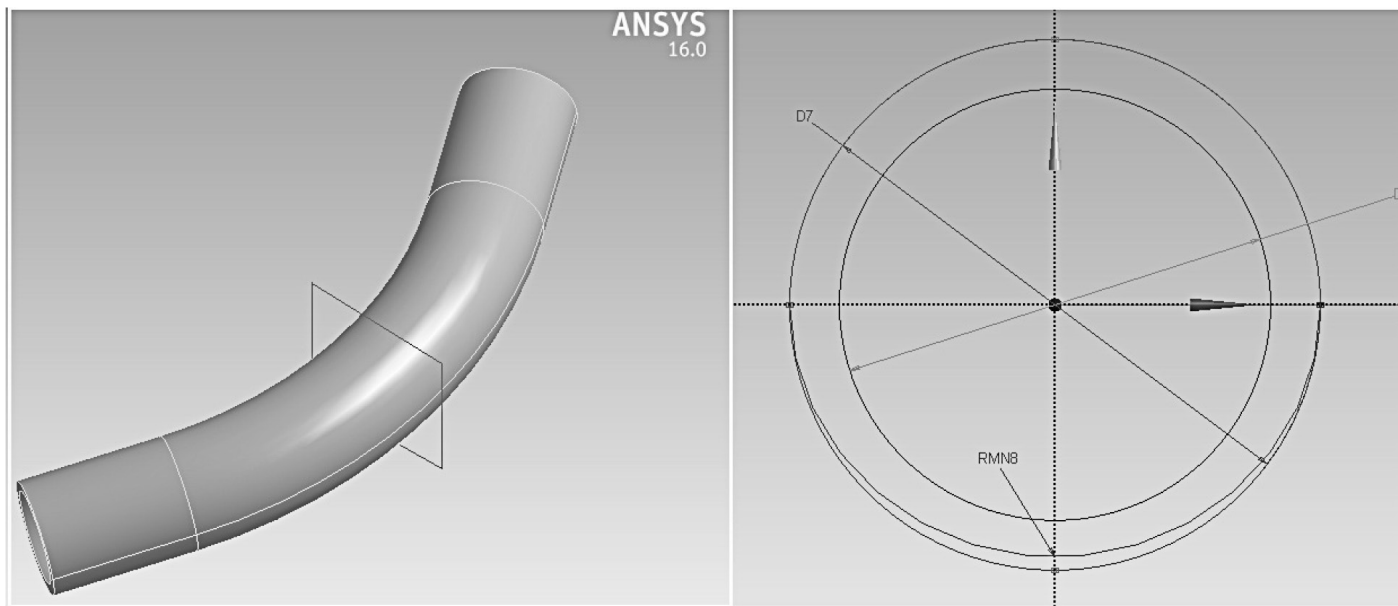

коррозии, образованию язв и питтингов, а также коррозионному растрескиванию под напряжением.

Приведенные сведения учтены при выборе граничных условий наиболее нагруженного участка линии ТОТ для определения целостности трубок. С учетом условий эксплуатации расчет прочности для оценки целостности трубок ТОТ выполнен в следующей последовательности:

1. Расчет прочности теплообменных трубок и оценка НДС в условиях скопления шлама, которое приводит к утончению стенки и изменению условий закрепления трубок в опорных местах. При этом в расчете прочности принимаются «консервативные» граничные условия с точки зрения влияния термических напряжений. Температура подаваемой воды в ПГ принимается равной $5{ }^{\circ} \mathrm{C}$. Расчет проводится для ряда случаев с различной степенью утончения стенки с целью определения критического значения утончения, после которого происходит потеря целостности трубки ТОТ.

2. Расчет прочности с учетом поведения трубок ТОТ в переходном процесс при граничных условиях для «оптимистичного» случая и оценка НДС во времени. При этом выбирается фрагмент, расположенный в зоне максимального скопления шлама, однако потеря металла вследствие влияния коррозионных процессов моделируется поверхностными трещинами на внешней и внутренней поверхностях теплообменной трубки.

Расчет прочности трубок теплообменной поверхности и оценка НДС при постуляции дефекта в виде утончения стенки. Допускаемые напряжения приняты в соответствии с положениями ПНАЭ Г-7-002-86 [3].

Опорные решетки, через которые проходят ТОТ, сконструированы таким образом, что при разогреве и расхолаживании трубки должны свободно перемещаться в опорных местах, т. е. дополнительных усилий и моментов в местах их крепления не возникает. Однако скопление шлама по длине трубки и в опорных местах может приводить к изменению условий опирания трубки. Поэтому дистанционирующие элементы системы опорных элементов реализованы моделированием упругих опор с расчетными характеристиками жесткостей $\mathrm{K}_{1}$ и $\mathrm{K}_{2}$, чтобы приблизить моделируемые условия к возможным реальным.

Дефект реализован в виде локального утончения толщины стенки на $20 \%$ и постулируется в месте локализации максимальных напряжений по результатам предварительного расчета.
Результаты расчета при заданных граничных условиях свидетельствуют о том, что в отдельных сечениях в месте утончения расчетные напряжения превышают допустимые по ПНАЭ Г-7-002-86 [3] напряжения и, более того, превышают пределы текучести и прочности материала ТОТ. При заданных нагрузках материал ТОТ выходит за границы работы в упругой зоне и работает в упругопластической зоне. Для уточнения НДС в этом случае определены упругопластические свойства материала ТОТ методом степенной аппроксимации диаграммы деформирования.

Расчет с учетом существующих дефектов выполнен на основе результатов вихретокового контроля теплообменных труб парогенераторов ПГВ-1000 на энергоблоке № 3 РАЭС с использованием установки «Siemens-Intercontrole».

Дефект реализован в виде локального утончения толщины стенки (рис. 4) и постулируется в месте локализации максимальных напряжений по результатам предварительного расчета.

Результаты расчета НДС трубки для утончения на $20 \%$ свидетельствуют о том, что при заданных «консервативных» граничных условиях целостность трубки сохранится. Далее для определения граничного значения утончения стенки, при котором возможно нарушение целостности ТОТ, рассмотрены варианты с утончением стенки ТОТ на 50, 60, 65, 70 и $80 \%$ (результаты расчета НДС для утончения стенки на 20, 50 и $80 \%$ см. в табл. 1). Проведенный итерационный расчет НДС показывает, что граничное значение, при котором происходит нарушение целостности трубки, $-80 \%$.

Таблица 1. Результаты расчета НДС для утончения стенки на 20, 50 и $80 \%$

\begin{tabular}{|c|c|c|c|}
\hline $\begin{array}{c}\text { Степень } \\
\text { утончения } \\
\text { стенки, \% }\end{array}$ & $\begin{array}{c}\text { Предел } \\
\text { текучести } \\
\boldsymbol{R}_{p 0,2}^{T}, \text { МПа }\end{array}$ & $\begin{array}{c}\text { Расчетное значение } \\
\text { напряжений } \sigma_{\text {max }}, \\
\text { МПа }\end{array}$ & $\begin{array}{c}\text { Предел } \\
\text { прочности } \\
\boldsymbol{R}_{m}^{T}, \text { МПа }\end{array}$ \\
\cline { 1 - 1 } 20 & & 254,94 & \multirow{2}{*}{412} \\
\cline { 1 - 1 } 50 & \multirow{2}{*}{177} & 270,22 & \\
\cline { 1 - 1 } 80 & & 415,28 & \\
\cline { 3 - 3 } & & \multicolumn{2}{|c|}{} \\
\cline { 3 - 3 } & & &
\end{tabular}

Расчет прочности ТОТ и оценка НДС при постуляции дефекта в виде трещины. По результатам теплогидравлического расчета для «оптимистичного» случая установлено, 


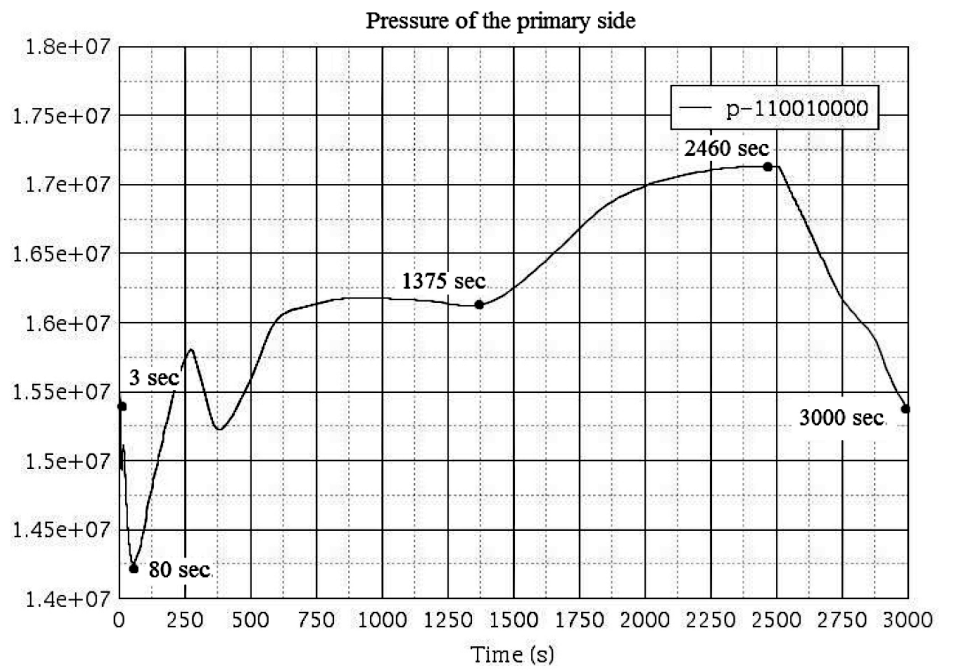

Pressure of the primary side

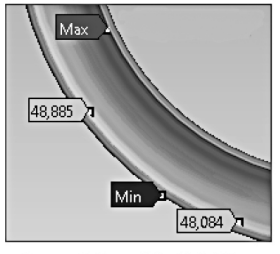

3 sec. $\mathrm{Max}=59,63 \mathrm{MPa}$

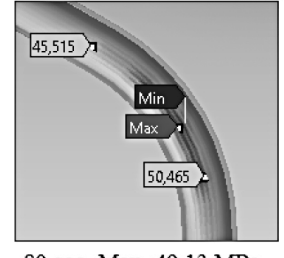

80 sec. $\operatorname{Max}=49,13 \mathrm{MPa}$

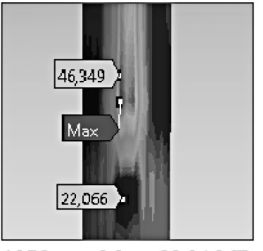

$1375 \mathrm{sec}$. Max=55,34 MPa

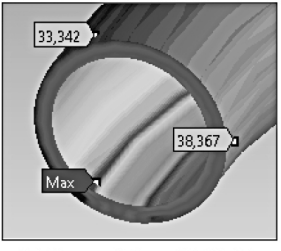

2460 sec. $\mathrm{Max}=59,7 \mathrm{MPa}$
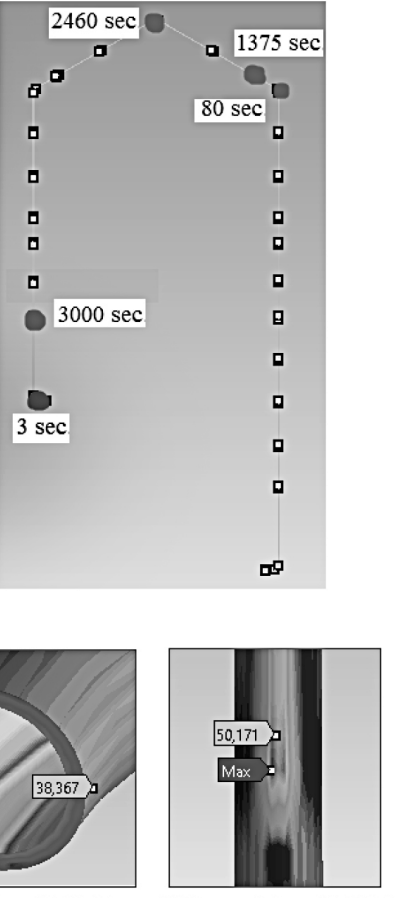

3000 sec. $\mathrm{Max}=54,63 \mathrm{MPa}$
Рис. 5. Определение экстремумов

эквивалентных напряжений при нестационарном режиме (временные точки и значения напряжений приведены на графике зависимости давления первого контура от времени) что температура воды второго контура в верхнем объеме трубчатки может быть принята в диапазоне $278-295{ }^{\circ} \mathrm{C}$.

С целью уточнения поведения ТОТ при протекании переходного процесса выполнен анализ НДС во времени. Результаты анализа (рис. 5) свидетельствуют о том, что экстремумы напряжений локализуются в зонах разных опорных элементов по всей длине исследуемой ТОТ.

Для оценки целостности ТОТ выбрана внешняя ТОТ верхнего слоя трубчатки, имеющая максимально большие расстояния между опорными элементами, с максимальными температурными деформациями. При этом для выбранной ТОТ приняты максимумы, полученные по результатам анализа НДС при переходном процессе, и выбран фрагмент, находящийся в зоне максимальной загрязненности шламом.

Основными характеристиками материала, используемыми в расчете, являются критический коэффициент интенсивности напряжений $K_{\text {Iс }}$, критическая температура хрупкости $T_{k}$ и предел текучести $R_{p 0,2}^{T}$. Сопротивление хрупкому разрушению считают обеспеченным, если для выбранного расчетного дефекта в виде трещины в рассматриваемом режиме эксплуатации выполняется условие $K_{\mathrm{I}}<\left[K_{\mathrm{I}}\right]$, где $\left[K_{\mathrm{I}}\right]-$ допустимое значение коэффициента интенсивности напряжений.

Учитывая картину локализации экстремумов напряжений и характер НДС в поперечном сечении, расположение трещины (рис. 6) принято перпендикулярно действующим окружным напряжениям в зоне 11-й дистанционирующей решетки, которая также является зоной максимального скопления шлама. В данном случае постулируется продольная трещина на нижней (опорной) стороне стенки линии ТОТ.

В рассмотренном случае размеры поверхностной полуэллиптической трещины согласно требованиям

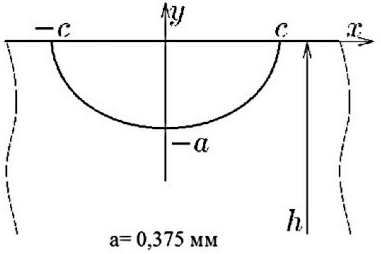

$\mathrm{c}=0,563 \mathrm{MM}$
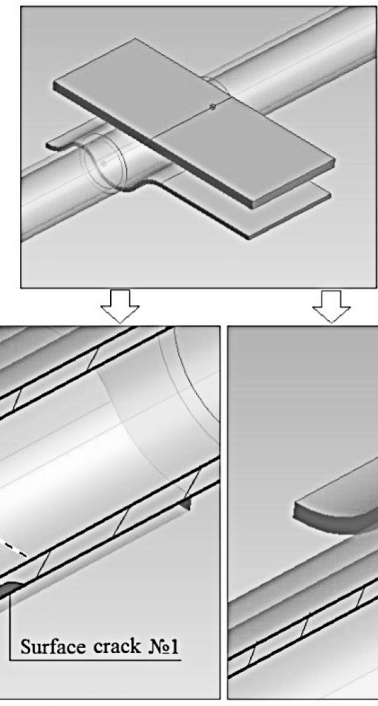

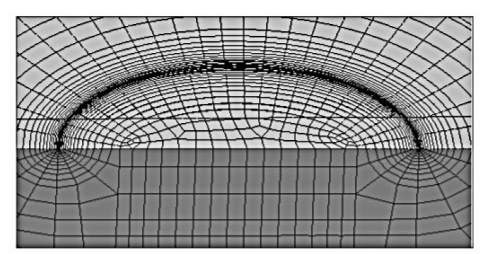

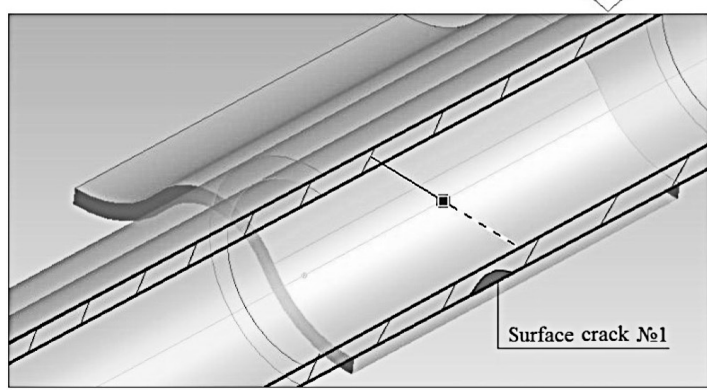

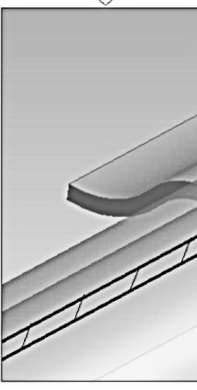

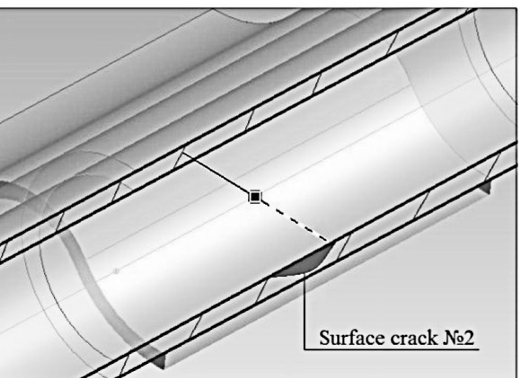

Рис. 6. Схема двух типов поверхностных трещин 


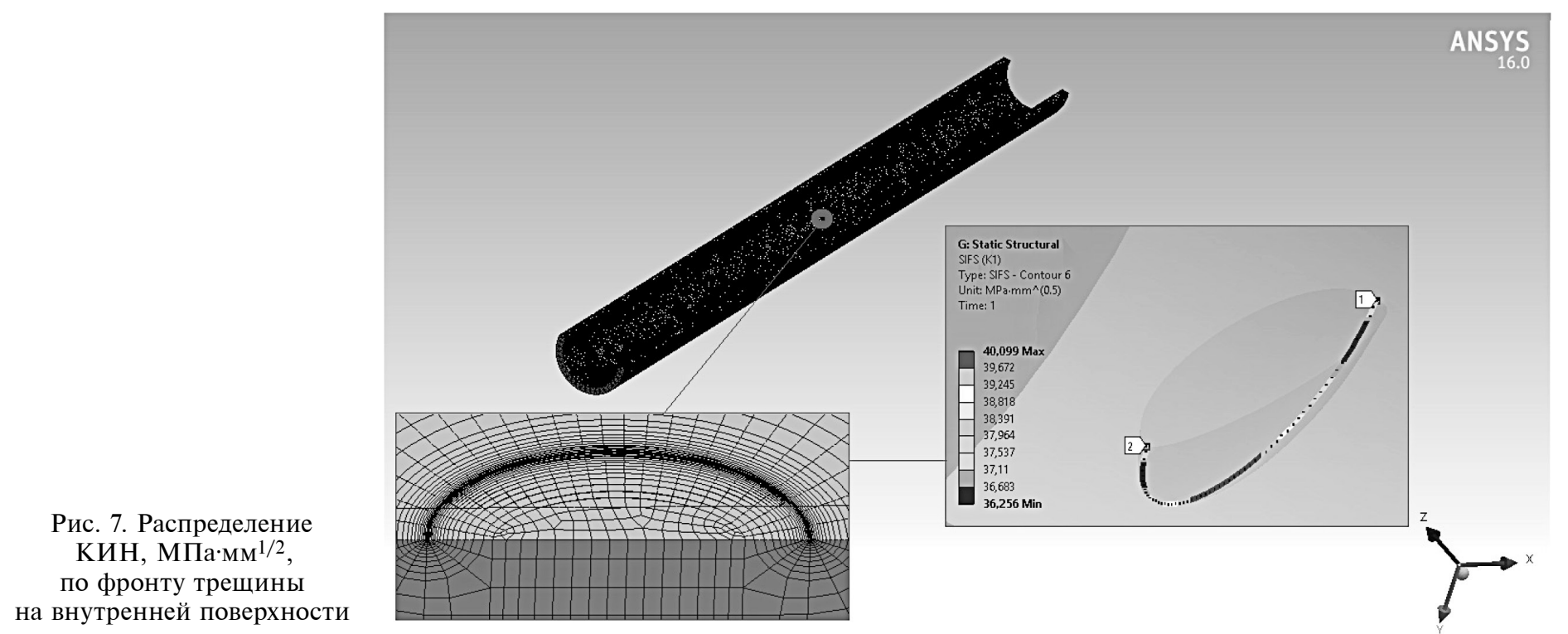

ПНАЭ Г-7-002-86 [3] приняты следующими: глубина $a=0,375$ мм, полудлина $l=0,563$ мм.

Постулирование трещины произведено в двух вариантах - для внешней и внутренней поверхностей.

Результаты расчета коэффициента интенсивности напряжений (КИН) по фронту трещины свидетельствуют о том, что максимальное значение КИН составляет $K_{\text {Імах }}=$ $=40 \mathrm{M \Pi а} \cdot \mathrm{Mм}^{1 / 2}=1,3 \mathrm{M \Pi а} \cdot \mathrm{M}^{1 / 2}$.

В настоящее время в нормативной документации Украины не регламентируется значение критического коэффициента интенсивности напряжений для стали аустенитного класса марки 08X18Н10T, из которой изготовлены ТОТ ПГ. Но вместе с тем существующие результаты исследований вязкости разрушения сталей ВКУ (аналогичной стали ТОТ) различных реакторов $[4,5,6]$ позволяют утверждать, что, в отличие от малолегированных и углеродистых сталей, аустенитные нержавеющие стали (в частности 08Х18Н10Т) не проявляют резкого вязко-хрупкого перехода.

Снижение их трещиностойкости, которое происходит вследствие нейтронного облучения, имеет тенденцию к постепенному накоплению по мере возрастания флюенса и насыщается при его уровнях более $1 \cdot 10^{21} \mathrm{H} / \mathrm{cm}^{2}$. Одни из исследований [6] трещиностойкости аустенитных сталей типа 304 для ВКУ реакторов кипящего типа при флюенсах от $1 \cdot 10^{21}$ до $6 \cdot 10^{21} \mathrm{H} / \mathrm{cm}^{2}$ показывают, что уровень насыщения трещиностойкости этих сталей составляет $55 \mathrm{MПа} \cdot \mathrm{M}^{1 / 2}$. Аналогичные закономерности [4, 5] выявлены для стали $10 \mathrm{X} 18 \mathrm{H} 9$ в диапазоне температур $20-400{ }^{\circ} \mathrm{C}$. Однако ТОТ ПГ не подвержены нейтронному облучению; принимая во внимание упомянутые факторы, в качестве критерия можно консервативно принять допустимое значение коэффициента интенсивности напряжений

$$
\left[K_{\mathrm{I}}\right]=55 \mathrm{M \Pi а} \cdot \mathrm{M}^{0,5} \text {. }
$$

Распределение КИН для постулированной трещины представлено на рис. 7.

Таким образом,

$$
K_{\mathrm{I} \max }=1,3 \mathrm{M \Pi а} \cdot \mathrm{M}^{0,5}<\left[K_{\mathrm{I}}\right]=55 \mathrm{M \Pi а} \cdot \mathrm{m}^{0,5} .
$$

В данном случае низкое значение КИН напряженнодеформированного состояния объясняется отсутствием силовых факторов как предпосылок для раскрытия постулируемых трещин.

\section{Выводы}

В данной работе начато исследование поведения ТОТ ПГ для оценки их целостности в условиях аварий с организацией подпитки полностью либо частично осушенного ПГ.

При проведении прочностного анализа приняты во внимание неопределенности результатов теплогидравлических анализов в части температуры охлаждающей воды в области трубчатки ПГ.

С учетом условий эксплуатации расчет прочности для оценки целостности ТОТ проведен в следующей последовательности:

1. Расчет прочности ТОТ и оценка НДС в условиях скопления шлама, которое приводит к утончению стенки и изменению условий закрепления трубок в опорных местах (температура подаваемой воды на стенку ТОТ принята равной $5{ }^{\circ} \mathrm{C}$, расчет выполнен для случаев с различной степенью утончения стенки, определено граничное значение утончения).

2. Расчет прочности с учетом поведения ТОТ при протекании переходного процесса (температура подаваемой воды на стенку ТОТ принята в диапазоне $278-295{ }^{\circ} \mathrm{C}$, НДС исследовано во времени, выбран фрагмент, расположенный в зоне максимального скопления шлама, дефект моделируется в виде поверхностной трещины на внешней и внутренней поверхностях теплообменной трубки).

Из результатов оценки целостности ТОТ по итогам анализа НДС при указанных условиях следует, что:

при самых неблагоприятных условиях попадания на стенку ТОТ холодной воды с температурой $5{ }^{\circ} \mathrm{C}$ и моделирования дефекта в виде потери металла (утончения стенки) ее целостность будет сохраняться вплоть до $80 \%$ утончения; при воздействии на стенку ТОТ воды с температурой $278-295{ }^{\circ} \mathrm{C}$ и представлении имеющихся дефектов в виде постулированных трещин (постулирование трещин выполнено в соответствии с требованиями 
ПНАЭ Г-87-002-86, глубина трещины - $25 \%$ толщины стенки трубки) результаты расчета свидетельствуют о сохранении целостности трубок ТОТ.

Анализ результатов, а также использованных в расчете допущений и упрощений свидетельствует о том, что изменение стратегии управления авариями только на основании полученных результатов является несколько преждевременным. Ряд факторов, влияющих на НДС трубок теплообменной поверхности, не могут считаться учтенными в полном объеме. Например, парогенератор - это сложная конструкция, в которой сочетаются разные материалы, различные толщины стенок конструктивных элементов, поэтому при возникновении локальных захолаживаний конструкции вследствие аварий поведение ПГ как цельной конструкции и его влияние на ТОТ невозможно спрогнозировать, для этого требуется проведение отдельного углубленного анализа.

На следующих этапах работ по доработке противоаварийных процедур и проведению углубленного анализа предполагаются:

разработка и верификация полномасштабной модели, включая корпус реактора, главный циркуляционный трубопроповод, компенсатор давления, главный циркуляционный насос, парогенератор, ТОТ для определения фактических усилий, которые действуют на ТОТ и элементы ПГ при эксплуатации;

сбор, анализ и систематизация сведений о выявленных дефектах в конструктивных элементах ПГ и ТОТ на энергоблоках АЭС Украины с целью определения наиболее представительных из них для дальнейших прочностных расчетов;

разработка и верификация детализированной теплогидравлической модели ПГ для получения исходных данных по температурным условиям на поверхностях ТОТ, коллекторов, корпуса ПГ;

выбор представительных аварийных сценариев и их теплогидравлический анализ;

прочностный анализ оценки целостности элементов ПГ (горячий и холодный коллектор, ТОТ) в условиях аварий для выбранных огибающих сценариев по результатам теплогидравлического анализа.

Реализация перечисленных шагов позволит с высокой степенью вероятности спрогнозировать поведение ПГ в условиях аварий и усовершенствовать противоаварийные процедуры (ИЛА, РУТА).

\section{Список использованной литературы}

1. Инструкция по ликвидации аварий и аварийных ситуаций на реакторной установке энергоблока № 3 Ривненской АЭС. Части 1-4. 3-ИЛА-РАЭС. К., 2013. 709 с.

2. Ривненская АЭС. Энергоблок № 3. Отчет по анализу безопасности. Техническое обоснование безопасности сооружения и эксплуатации АЭС. Кн. 10. Гл. 3 : Описание важных для безопасности систем, оборудования и сооружений АС. Системы 3.33.3.1. 22.3.133.ОБ.13.10 АТ03-13.2110.ОД.2. К., 2014. 290 с.
3. ПНАЭ Г-7-002-86. Нормы расчета на прочность оборудования и трубопроводов атомных энергетических установок. М. : Энергоатомиздат, 1989. 524 с.

4. Марголин Б. З., Минкин А. И., Смирнов В. И., Федорова В. А., Кохонов В. И., Козлов А. В., Евсеев М. В., Козманов Е. А. Исследование влияния нейтронного облучения на статическую и циклическую трешиностойкость хромоникелевой аустенитной стали. Вопросы материаловедения. 2008. Т. 53, № 1. С. 123-138.

5. Марголин Б. 3., Курсевич И. П., Сорокин А. А., Лапин А. Н., Кохонов В. И., Неустроев В. С. Охрупчивание и трещиностойкость высокооблученных аустенитных сталей для элементов ВКУ ВВЭР. Сообщение 1 : Связь радиационного распухания с радиационным охрупчиванием - экспериментальные результаты. Проблемы прочности. 2009 № 6. С. 5-16.

6. IAEA-TECDOC-1557. Assessment and Management of Ageing of Major Nuclear Power Plant Components Important to Safety: PWR Vessel Internals, 2007 Update. Vienna : IAEA, 2007. 65 p.

\section{References}

1. Emergency Operating Procedure at Rivne NPP Unit 3, Parts 1-4, 3-ILA-RAES [Instruktsyia po likvidatsii avarii i avariinykh situatsii na reaktornoi ustanovke energobloka No. 3 Rivnenskoi AES], Kyiv, 2013, 709 p. (Rus)

2. Rivne NPP. Unit 3. Safety Analysis Report. Technical Safety Justification of NPP Construction and Operation, Book 10, Chapter 3: Description of Systems, Structures and Components Important to Safety [Rivnenskaia AES. Energoblok No. 3. Otchiot po analizu bezopasnosti. Tekhnicheskoie obosnovaniie bezopasnosti sooruzheniia i ekspluatatsii AES. Kn. 10. Gl. 3: Opisaniie vazhnykh dlia bezopasnosti sistem, oborudovaniia i sooruzhenii AS], Systems 3.3-3.3.1. 22.3.133. OB.13.10 AT03-13.2110.OD.2, Kyiv, 2014, 290 p. (Rus)

3. PNAE G-7-002-86. Rules of Strength Calculation for Equipment and Piping of Nuclear Power Plants [Normy raschiota na prochnost oborudovaniia i truboprovodov atomnykh energeticheskikh ustanovok], Moscow, Energoatomizdat, 1989, 524 p. (Rus)

4. Margolin, B. Z., Minkin, A. I., Smirnov, V. I., Fiodorova, V. A., Kokhonov, V. I., Kozlov, A. V., Yevseev, M. V., Kozmanov, Ye. A. (2008), "Research of Neutron Radiation Impact on Static and Cyclic Crack Resistance of Chromium Nickel Austenitic Steel" [Issledovaniia vliianiia neitronnogo oblucheniia na staticheskuiu i tsyklicheskuiu treshchinostoikost khromnikelevoi austenitnoi stali], Material Science Issues, V. 53, No. 1, pp. 123-138. (Rus)

5. Margolin, B. Z., Kursevich, I. P., Sorokin, A. A., Lapin A. N., Kokhonov, V. I., Neustroiev, V. S. (2009), "Embrittlement and Crack Resistance of Highly Exposed Austenitic Steels for VVER Reactor Internals. Message 1: Connection of Radiation Swelling with Radiation Embrittlement - Experimental Results" [Okhrupchivaniie i treshchinostoikost vysoloobluchionnykh austenitnykh stalei dlia elementov VKU VVER. Soobshcheniie 1: Sviaz radiatsionnogo raspukhaniia s radiatsionnym okhrupchivaniiem - eksperimentalnyie rezultaty], Strength Problems, No. 6, pp. 5-16. (Rus)

6. IAEA-TECDOC-1557. Assessment and Management of Ageing of Major Nuclear Power Plant Components Important to Safety, PWR Vessel Internals, 2007 Update, Vienna, IAEA, 2007, 65 p. 